\title{
Interstitial pneumonitis during rituximab- containing chemotherapy for primary central nervous system lymphomas: a case report and review of literature
}

\author{
Yuchen Wu, Xuefei Sun, Jing Liu, Jun Qian, Xueyan Bai, Yuedan Chen and Yuanbo Liu*
}

\begin{abstract}
Background: Primary central nervous system lymphoma(PCNSL) is a rare kind of non-Hodgkin lymphoma. Rituximab combined with high-dose methotrexate, cytarabine and dexamethasone (R-MAD regimen) were reported effective for PCNSL patients. Rituximab can cause several side effects, including fever, chills and rigors.

Case presentation: In this case report, we demonstrate rituximab-induced interstitial pneumonitis in a PCNSL patient who has been treated with R-MAD regimen. The patient recovered after treatment and she remains complete remission after following consolidation chemotherapy.

Conclusions: Here is no report of potential fatal complications of Rituximab like interstitial pneumonitis nowadays in PCNSL patients. As Rituximab is widely used, physicians should raise their awareness of this rare complication and detect RTX-ILD in early stage.
\end{abstract}

Keywords: Central nervous system neoplasm, Lymphoma, Interstitial pneumonitis, Rituximab, R-MAD regimen, Rituximab induced lung disease, Chemotherapy, Immunotherapy

\section{Background}

Primary central nervous system lymphoma(PCNSL)are extranodal Non-Hodgkin lymphomas confined to the brain, eyes, leptomeninges, or spinal cord in the absence of systemic lymphoma,and is predominantly (90-95\%) of the diffuse large B-cell lymphoma (DLBCL) subtype [1]. Methotrexate containing regiment(high-dose methotrexate(MTX) with cytarabine(Ara-C) and dexamethasone) is presently considered as the first choice for PCNSL patients whose preparing to take chemotherapy. Rituximab(RTX) is a chimeric anti-CD20 monoclonal antibody. It is reported that the complete response rate and overall survival in PCNSL accessed to high-dose methotrexatecontained regiment can be improved with the addition of Rituximab [2]. We previously retrospective analyzed 35 PCNSL patients in hematology department of Beijing Tiantan hospital who received R-MAD regimen and prove

\footnotetext{
* Correspondence: yuanbol@ccmu.edu.cn

Department of Hematology, Beijing Tiantan Hospital, Capital Medical University, Beijing 100050, China
}

its safety and effectiveness [3]. During the infusion of RTX, there can be some common side effect including fever, chills, and rigors. Severe respiratory conditions have never been reported in PCNSL patient before. To raise awareness of this serious complication of RTX containing treatment, we demonstrate rituximab-induced interstitial pneumonitis in a PCNSL patient who has been treated with R-MAD(Rituximab, high-dose methotrexate, cytarabine, and dexamethasone) regimen.

\section{Case description}

Four months ago, a 33y female patient complained low fever with acratia, night sweating, and disorder of left limb's activity. Her brain CT showed right lateral ventricle occupying lesion. Postoperative pathology showed diffuse large B-cell lymphoma, after which she received 5 cycles of R-MAD regimen (Rituximab $600 \mathrm{mg}$ d1, high-dose methotrexate, cytarabine, and dexamethasone) chemotherapy (Fig. 1). Then her left limbs activity fully recovered. 


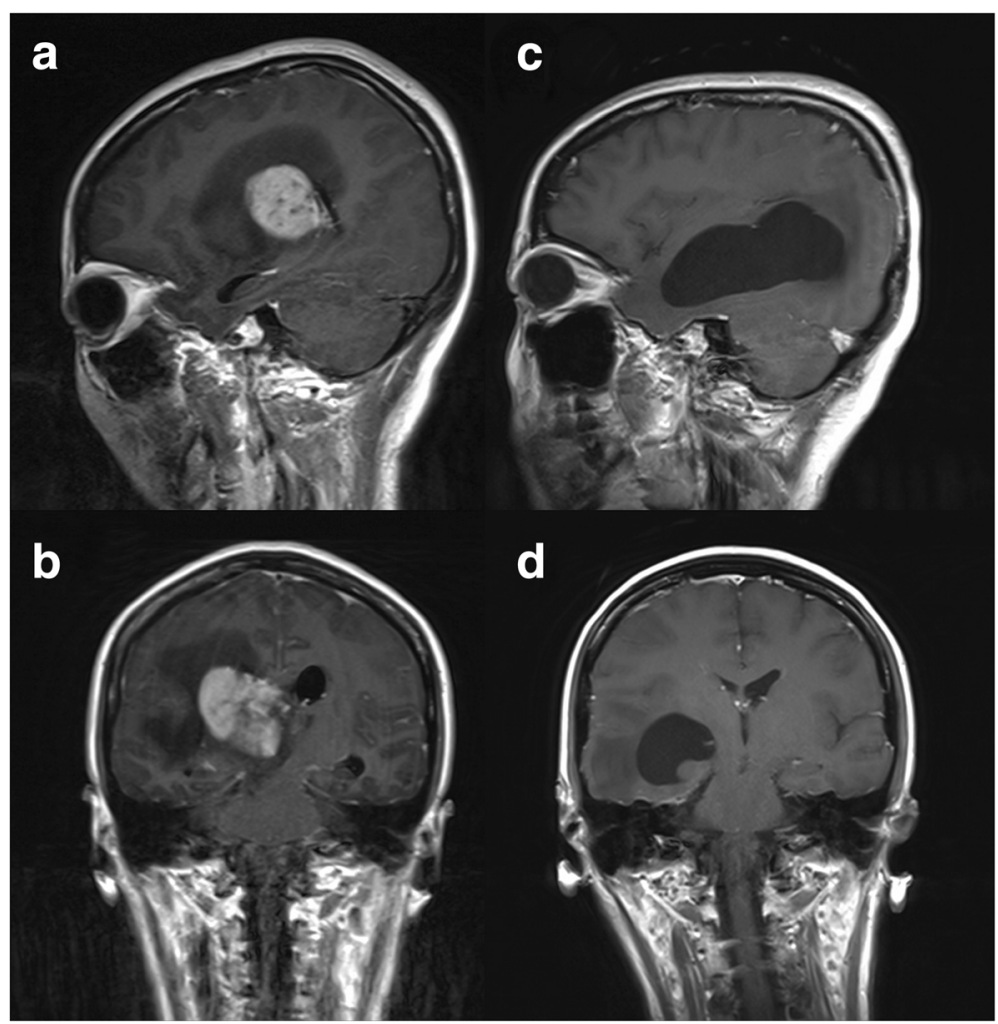

Fig. 1 a, b MRI enhancement revealed: on the right side of the thalamus a block of long T2 long T1 signal can be seen,the boundary is clear, the range is $44 \times 40 \times 34 \mathrm{~mm}$. Enhanced scanning showed inhomogeneous enhancement. Massive edema can be seen around the lesion. The third ventricle was compressed,bilateral ventricles dilated. Midline shift left slightly. $\mathbf{c}, \mathbf{d}$ MRI enhancement after surgery and 5 cycles of R-MAD chemotherapy showed: right side of the occipital skull and soft tissue post operation change. The right lateral ventricles triangle and the temporal angle were irregular enlarged, the ventricular wall was less structured

Two weeks after the fifth cycle of R-MAD regimen chemotherapy (Rituximab $600 \mathrm{mg}$ d1, high-dose methotrexate, cytarabine, and dexamethasone), she was admitted to hospital with the symptoms of fever and abdominal pain. The physical examination revealed temperature $38.7{ }^{\circ} \mathrm{C}$; pulse $82 / \mathrm{min}$; respiration 20 times/min; blood pressure 120/80 mmHg; Clear consciousness; mild anemic appearance; no swelling of superficial lymphnode. Her chest was clear to percussion and auscultation, and her heart and abdomen showed no abnormality, also, her lower limbs has no swelling. Blood routine: white cell count(WBC) $4.68 \% 10^{9} / \mathrm{L}$, percentage of neutrophilic granulocyte 75.9\%, hemoglobin $119 \mathrm{~g} / \mathrm{l}$, platelet count $55^{*} 10^{9} / \mathrm{L}$. Stool routine: red blood cell $(-/ \mathrm{HPF})$, white blood cell count(- /HPF), occult blood(-), fungi(- /HPF).

Preliminary diagnosis was a gastroenteritis caused by unhygienic food. Cefmetazole were prescribed for her. After using cefmetazole for 1 day, her temperature raised up to $40{ }^{\circ} \mathrm{C}$.Blood routine: white blood cell count $2.08^{*} 10^{9} / \mathrm{L}$, neutrophilic granulocyte $1.26^{*} 10^{9} / \mathrm{L}$, hemoglobin $101 \mathrm{~g} / \mathrm{l}$, platelet count $80^{*} 10^{9} / \mathrm{L}$. C-reactive protein $20.05 \mathrm{mg} / \mathrm{L}$. Procalcitonin $<0.05 \mathrm{ng} / \mathrm{ml}$. X-ray examination showed intensification of pulmonary grains, bilateral exudative change, suggesting pulmonary infection. So, meropenem was given. Though the patient complained no cough, no expectoration or dyspnea, she had cyanosis and bilateral coarse breath sounds on pulmonary auscultation. Blood gas demonstrated type I respiratory failure ( $\mathrm{pH} 7.44, \mathrm{PaO}_{2} 41 \mathrm{mmHg}, \mathrm{PaCO}_{2} 34 \mathrm{mmHg}, \mathrm{SaO}_{2}$ $78 \%)$. Chest CT demonstrated bilateral lung fields with diffuse ground glass opacities, compatible with interstitial pneumonitis (Fig. 2).

Blood routine, procalcitonin, c-reactive protein retesting results suggested severe infectious pneumonia. If the infection of pulmonary was the only existing pathogenesis, the patient should have responded to antibiotics treatment, but turned out not. Thus, rituximab induced lung disease (RTX-ILD) was considered possible. After that high-dose intravenous steroid ( $80 \mathrm{mg}$ urbason) was given immediately with continuous meropenem treatment. One day after intravenous steroid, her temperature back to normal. Arterial blood gas changes see in Table 1. CT reexamination revealed significant lesion absorption, and normal pulmonary grain after seven-day steroid treatment (Fig. 2). In addition, her chest was clear to percussion and auscultation, and her saturation of blood oxygen was at normal 


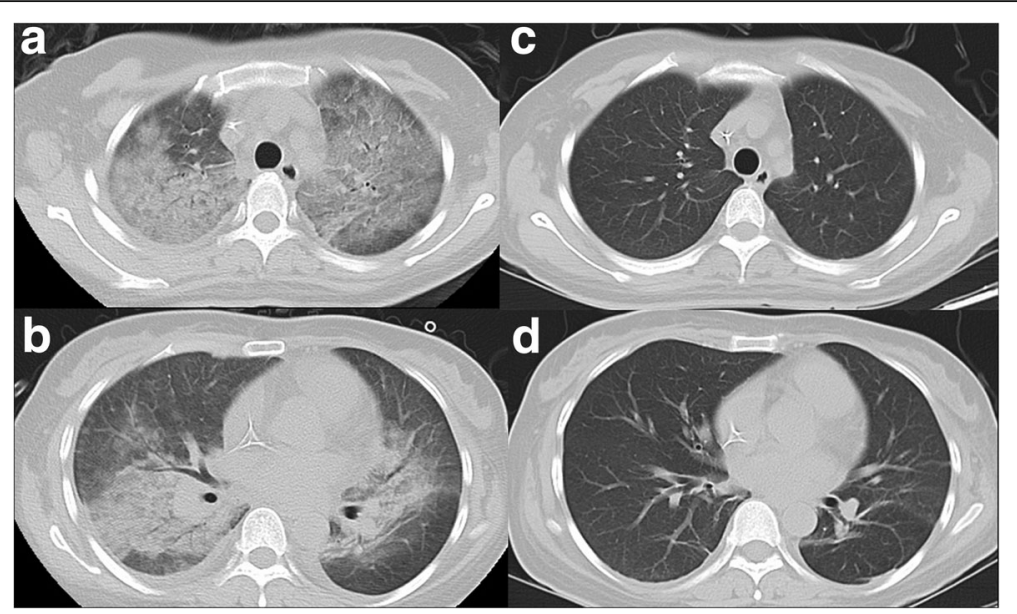

Fig. 2 a, b Helical computed tomographic scanning showing bilateral diffuse ground glass opacities, partialpleura thickening, crescent shaped liquid density of bilateral chest wall. c, d A repeat CT scan 7 days after glucocorticoid and antibiotic therapy showing almost complete resolution of the interstitial infiltration

level. After that, the patient received two cycles of pemetrexed and two cycles of EA regimen (Etoposide and cytarabine) as consolidation chemotherapy. There were no signs of recurrence of lymphoma on the following MRI and PET scan of the patient.

\section{Discussion}

Rituximab(RTX) has been proved effectively in treating malignant and autoimmune disease including: lymphoma, leukemia, rheumatoid arthritis, Wegeners granulomatosis [4], and benefit non-Hodgkin's lymphoma (NHL) and RA patients $[5,6]$. Infusion-related symptom complex have been observed during the use of RTX which consists fever, chills and rigors. During clinical trials, 9-15\% of the patients showed symptoms of infusion-related reactions, while $30 \%$ of patients had respiratory manifestations (cough, bronchospasm, sinusitis and rhinitis). These complications are generally mild and self-limited. Severe side effects such as anaphylactic shock and acute respiratory distress syndrome were rare, fatal in $0.04-0.07 \%$. Interstitial lung disease is one of those potentially fatal complications of RTX therapy, it is reported that the overall incidence of RTX-ILD is less than $0.03 \%$ in phase III trials [7]. However, it is reviewed that in post-marketing literature the

Table 1 Change of arterial blood gas

\begin{tabular}{llll}
\hline & Day 1 & Day 2 & Day 5 \\
\hline $\mathrm{PH}$ & 7.44 & 7.44 & 7.52 \\
Partial pressure of carbon dioxide $\left(\mathrm{PaO}_{2}\right) / \mathrm{mmHg}$ & 34 & 36 & 38 \\
Partial pressure of oxygen $\left(\mathrm{PO}_{2}\right) / \mathrm{mmHg}$ & 41 & 156 & 81 \\
Saturation of oxygen/\% & 78 & 97 & 97 \\
$\mathrm{PO}_{2} / \mathrm{FiO}_{2}$ & 195 & 390 & 324 \\
\hline
\end{tabular}

incidence is much higher, ranging from $3.7-10 \%$ [4].The variance between these two incidences might due to different in target population. Phase III trials shown that RTX-ILD is of more severity in lymphoma than in rheumatological disorders, which may due to the difference of dosage used in treatment [8]. As for hematological disorders, the mean dosage of RTX was $7785 \mathrm{mg}$ comparing to $2000 \mathrm{mg}$ in rheumatological disorders. RTX is widely used for patients with B cell lymphoma and the majority case reports are from non-Hodgkin lymphoma patients. According to the previous research of our department, we found that with the use of RTX, the probability of complete response and overall survival in newly diagnosed PCNSL patients had been improved [1]. And this is the first time that R-ILD has been discovered in PCNSL patients.

The pathogenesis of R-ILD remains unclear. One hypothesis is pathogenic cytokine release. Tumor necrosis factor- $\alpha($ TNF- $\alpha)$ and interleukins are thought to be the dominating contributing cytokines $[9,10]$. Recently there was case reported that Nod-like receptor pyrin domaincontaining protein 3(NLRP3)may act as an initiator of inflammation process in lung of R-ILD patient. The discovery of NLRP3 and related further researches could open a new sight into the pathologic mechanism and provide a new target for the treatment of RTX-ILD [11].

Rituximab induced lung disease have higher incidence in male and patient of their fifty to sixty. Mostly occurring 2 weeks after the latest cycle of infusion, the fourth cycle of RTX [12], average dose accumulated to $1500 \mathrm{mg} / \mathrm{m}^{2}$. Common complains of RTX-ILD included: dyspnea and cough. Other symptoms like fatigue, rigours, wheeze, hemoptysis, skin rash have also been reported. About $20.7 \%$ of the cases is detected radiologically without 
symptoms. Physical examinations may be unremarkable or without diffuse fine inspiratory crackles. As for typical radiological abnormalities, chest radio graph displaying diffuse bilateral lung infiltrates. In high-resolution or helical thoracic CT, ground-glass opacification(GGO), alveolitis, pulmonary fibrosis, alveolar hemorrhage, pleural effusions and consolidation can also be seen. PET-CT could indicate the activation of neutrophil within the lungs by showing 18-FDG accumulation in hypermetabolic lung nodules. Lung biopsy is not usually performed in RTXILD, in our case, the diagnosis was made on clinical and radiological basis. Her respiratory symptoms relieved greatly after steroid treatment thus we didn't see the further need for invasive investigation. Anyway, pulmonary inflammation is a common feature in reported cases. A recent systematic review of the available studies showed various histological patterns including: organizing pneumonia, interstitial pneumonitis, desquamative interstitial pneumonia, diffuse alveolar damage, and usual interstitial pneumonia [13].

According to Wagner's review, hypoxemia and saturation of blood oxygen decreasing is uniformly abnormal in RTX-ILD [14]. There's also research signify fever was the most common presenting symptom [15].

In our case report, the patient was free of respiratory symptoms and no abnormal objective sign in lung except for cyanosis is a crucial clue, suggesting hypoxemia. Following arterial blood gas testing confirmed type I respiratory failure. Pulmonary function tests reveal restrictive pattern on spirometry and significant reduction in carbon monoxide diffusion capacity. Further test could be done to confirm diagnosis and evaluate the efficacy of treatment, like transbronchial lung biopsy, bronchoalveolarlavage. Blood culture, sputum culture, antineutrophil cytoplasmic antibody, procalcitonin, antibodies and DNA testing for acute virus and empirical treatment with antibiotics should be down to rule out bacterial infection.

Once RTX-ILD was considered, RTX treatment should be stopped immediately and provide intravenous steroid. Supporting treatment include oxygen-inspiration and noninvasive mechanical ventilation can be provided contingent on blood oxygen. RTX-ILD patients who do not respond to glucocorticoids is potential fatal. In a 21-day treatment, $5 \mathrm{mg}$ of dexamethasone or $40 \mathrm{mg}$ of methyl-prednisolone were used in the first three consecutive days, followed by prednisone taken orally with slow taper. ${ }^{14}$ Treatment for such severe RTX-ILD is still challenging. Some authors have suggested anti-TNF $\alpha$ therapy in severe cases. The first TNF- $\alpha$ antagonist and cytokine profiling treating was published by Yong-Kang $\mathrm{Wu}$, but the he did not obtain an ideal outcome. Moreover, some clinical trials even indicated that TNF- $\alpha$ antagonists themselves may lead to a worse prognosis [16].
The retreatment of rituximab may probably deteriorate pulmonary condition among the patients who had experience R-ILD [17, 18]. However some other reports presented opposite result. Those patients who has been retaken Rituximab contained regimens showed uneventful outcome [19]. Therefore, the decision should be made carefully. As the probability of curing the disease may be improved while the incident rate of potential pulmonary toxicity may be improved as well [14].

\section{Conclusion}

Rituximab is widely used in non-Hodgkin lymphomas including PCNSL. Rituximab induced lung disease is a rare yet potential fatal complication. Early diagnosis and treatment including intravenous glucocorticoids, oxygeninspirationare are of great importance. To detect RTX-ILD in early stage, physicians subscribing RTX should be clearly aware of its common and rare complications, once patients applying RTX appear cyanosis or hypoxemia, futher examinations including arterial blood gas test and chest CT should be done as soon as possible. The pathogenesis of RTX-ILD remains unclear, NLRP3 may provide a new target for treatment in the future.

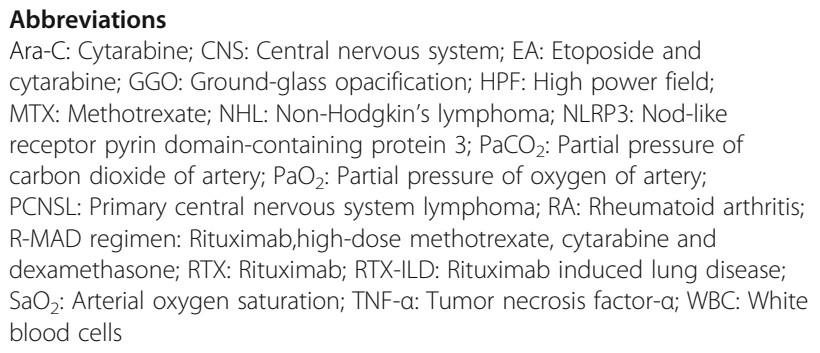

\section{Acknowledgments}

This study was supported by department of hematology, Beijing Tiantan Hospital, Capital Medical University.

\section{Funding}

National Natural Science Foundation of China (81272842) and Beijing Natural Science Foundation of China (7172071).

\section{Availability of data and materials \\ The data sets used during the current study are available from the corresponding author on reasonable request.}

\section{Authors' contributions \\ $\mathrm{XS}, \mathrm{XB}$ and $\mathrm{YC}$ participated in diagnosis and therapeutic process of the patient, YW was a major contributor in writing the manuscript, JL provided language instruction. All authors read and approved the final manuscript.}

Ethics approval and consent to participate Not applicable.

\section{Consent for publication}

The clinical details and images was obtained from the patient with written informed consent for publication.

Competing interests

The authors declare that they have no competing interests. 
Received: 8 November 2017 Accepted: 10 December 2017

Published online: 08 January 2018

\section{References}

1. Wang CC, Carnevale J, Rubenstein JL. Progress in central nervous system lymphomas[J]. Br J Haematol. 2014;166:311-25.

2. Ferreri AJ, Reni M, Foppoli M, et al. High-dose cytarabine plushigh-dose methotrexate versus high-dose methotrexate alone inpatients with primary CNS Iymphoma: a randomised phase 2 trial. Lancet. 2009;374:1512-20.

3. Xuefei $S$, Jin L, Shengju S, et al. Efficacy of rituximab combined with chemotherapy regimen for the treatment of primary centralnervous system lymphomas. Chin J Neurosurg. 2016;32:388-92.

4. Montero AJ, McCarthy JJ, Chen G, Rice L. Acute respiratory distress syndrome after rituximab infusion. Int J Hematol. 2005;82:324-6.

5. Coiffier B, Lepage E, Briere J, et al. CHOP chemotherapy plus rituximab compared with $\mathrm{CHOP}$ alone in elderly patients with diffuse large-B-cell lymphoma. N Engl J Med. 2002;346(4):235-42.

6. Czuczman MS, Gregory SA. The future of CD20 monoclonal antibody therapy in B-cell malignancies. Leuk Lymphoma. 2010;51(6):983-94.

7. Liu X, Hong XN, Gu YJ, Wang BY, Luo ZG, Cao J. Interstitialpneumonitis during rituximab-containing chemotherapy fornon-Hodgkin lymphoma. Leuk Lymphoma. 2008;49(9):1778-83.

8. Shaw T, Quan J, Totoritis MC. B cell therapy for rheumatoid arthritis: the rituximab (anti-CD20) experience. Ann Rheum Dis. 2003;62(Suppl. 2):ii55-9.

9. Schmidt K, Martinez-Gamboa L, Meier S, et al. Bronchoalveoloar lavage fluid cytokinesand chemokines as markers and predictorsfor the outcome of interstitia lungdisease in systemic sclerosis patients. ArthritisRes Ther. 2009;11:R111.

10. Vasakova M, Sterclova M, Kolesar L, et al. Bronchoalveolar lavage fluid cellular characteristics,functional parameters and cytokine and chemokine levels in interstitial lung diseases. Scand J Immunol. 2009;69:268-74.

11. Kong H, Wang Y, Zeng X, Zhu Q, Xie W, Dai S. Involvement of NLRP3 inflammasome in rituximab-induced interstitial lung disease: a case report. J Clin Pharm Ther. 2014:39(6):691-4.

12. Lioté $H$, Lioté $F$, Séroussi $B$, et al. Rituximab-induced lung disease: a systematic literature review. Eur Respir J. 2010;35:681-7.

13. Hadjinicolaou AV, Nisar MK, Parfery $H$, Chilvers ER, Ostör AJ. Non-infectious pulmonary toxicity of rituximab: a systematic review. Rheumatology (Oxford). 2012;51(4):653-62.

14. Wagner SA, Mehta AC, Laber DA. Rituximab-induced interstitial lung disease Am J Hematol. 2007;82:916-9.

15. Liu X, Hong X-N, Ya-Jia G, Wang B-Y, Luo Z-G, Cao J-N. Interstitial pneumonitis during rituximab-containing chemotherapy for non-Hodgkin lymphoma. Leuk Lymphoma. 2008;49(9):1778-83.

16. Tan J. Ni X.TNF-a antagonist may not be suitable for severe rituximabinduced interstitial lung disease. J Clin Pharm Ther. 2015;40(3):249-50.

17. Alexandrescu DT, Dutcher JP, O'Boyle K, Albulak M, OisethS WPH. Fatal intraalveolar hemorrhage after rituximab in a patient with non-Hodgkin lymphoma. Leuk Lymphoma. 2004:45:2321-5.

18. Kanelli S, Ansell SM, Habermann TM, Inwards DJ, Tuinstra N, Witzig TE. Rituximab toxicity in patients with peripheral blood malignant B-cell lymphocytosis. Leuk Lymphoma. 2001;42:1329-37.

19. Byrd JC, Peterson BL, Morrison VA, Park K, Jacobson R, Hoke E, et al. Randomized phase 2 study of fludarabine with concurrent versus sequential treatment with rituximab in symptomatic, untreated patients with B-cell chronic lymphocytic leukemia: results from cancer and leukemia group B 9712 (CALGB 9712). Blood. 2003;101:6-14.

\section{Submit your next manuscript to BioMed Central and we will help you at every step:}

- We accept pre-submission inquiries

- Our selector tool helps you to find the most relevant journal

- We provide round the clock customer support

- Convenient online submission

- Thorough peer review

- Inclusion in PubMed and all major indexing services

- Maximum visibility for your research

Submit your manuscript at www.biomedcentral.com/submit
C) Biomed Central 